\title{
Assessment of Retreatment Tuberculosis Cases amongst All Tuberculosis Cases Notification in District Swat 2015-2017: A Retrospective Cohort Review
}

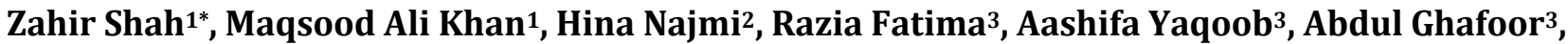 \\ Ahmed Wali ${ }^{4}$, Amjad Khan', Shah Hasan Khan1, Ghulam Mustafa Halepota1 \\ ${ }^{1}$ Provincial Tuberculosis Control Program, Swat, Khyber Pakhtunkhwa, Pakistan \\ ${ }^{2}$ Sukh Initiative, Aman Health Care Services, Karachi, Pakistan \\ ${ }^{3}$ National Tuberculosis Control Program, Islamabad, Pakistan \\ ${ }^{4}$ Provincial Tuberculosis Control Program, Quetta, Pakistan \\ ${ }^{5}$ Pakistan Kidney and Liver Institute \& Research Center, Lahore, Pakistan \\ Email: *drzahirshah61@gmail.com
}

How to cite this paper: Shah, Z., Khan, M.A., Najmi, H., Fatima, R., Yaqoob, A., Ghafoor, A., Wali, A., Khan, A., Khan, S.H. and Halepota, G.M. (2019) Assessment of Retreatment Tuberculosis Cases amongst All Tuberculosis Cases Notification in District Swat 2015-2017: A Retrospective Cohort Review. Journal of Tuberculosis Research, 7, 11-18.

https://doi.org/10.4236/jtr.2019.71002

Received: November 15, 2018

Accepted: March 1, 2019

Published: March 4, 2019

Copyright $\odot 2019$ by author(s) and Scientific Research Publishing Inc. This work is licensed under the Creative Commons Attribution International License (CC BY 4.0).

http://creativecommons.org/licenses/by/4.0/ (c) () Open Access

\begin{abstract}
Retreatment Tuberculosis (TB) has long been a neglected area in global TB control. To determine the notification of re-treatment Tuberculosis TB cases among all enrolled TB patients, we conducted a retrospective cohort review of routine program data from 2015-2017. A total of 8663 tuberculosis cases (all new and old forms) were registered at the study site. Of these, 1916 (22\%) were pulmonary bacteriological confirmed; 3498 (40.37\%) were pulmonary clinical diagnosed and 3396 (39.20\%) were clinically or bacteriological confirmed extra-pulmonary tuberculosis cases. Retreatment cases trend was found to be increased from $1 \%$ in 2015 to $1.6 \%$ in 2017. Majority of re-treatment cases were in the age group $18-43$ years and only 7 patients were under the age of 15 years. This concludes that notification of re-treatment cases is very low among all enrolled TB patients and this could be possibly due to the fact that most of the re-treatment cases were registered as new cases or misdiagnosed. There is need and space to increase retreatment cases. Most of the re-treatment cases were usually converted to MDR-TB (Multi-Drug Resistant Tuberculosis) as noted in PMDT (Programmatic management of Drugs resistant tuberculosis) site. Therefore, proper history and diagnosis should be encouraged at the time of case notification.
\end{abstract}

\section{Keywords}

Retreatment TB Cases, Retrospective Cohort, Swat Pakistan 


\section{Introduction}

TB is a major public health problem worldwide. It is necessary for treatment of tuberculosis to be successful. Anti-tuberculosis drugs should be taken for a minimum period of six months for non-resistant pulmonary tuberculosis or sometimes 12 to 24 months in the case of extra-pulmonary and resistant tuberculosis [1]. Patients with retreatment tuberculosis (TB) represent those who have been treated previously for more than one month with anti-TB drugs and who have been diagnosed again with the disease. These patients mainly include relapses, treatment after failure, or loss to follow-up on a first-line treatment regimen [2].

The detection and management of re-treatment $\mathrm{TB}$ cases have remained a challenge for the national TB control programs worldwide [3] [4]. World Health Organization (WHO) globally estimated that $3.5 \%$ of new TB cases and $18 \%$ of previously treated cases had MDR/RR-TB (Multidrug-resistant tuberculosis; Rifampicin resistance), and also 10.0 million people developed TB disease in 2017 I in which 5.8 million were men, 3.2 million were women, and 1.0 million were children. In Pakistan, New and relapse cases registered in 2016 were 356,390 with success rate $94 \%$, while previously treated cases, excluding relapse, registered in 2016 was 9671 with success rate $78 \%$ while MDR/RR-TB cases started on second-line treatment in 2015 were 2544 and XDR-TB (Extreme Drug Resistance tuberculosis) cases started on second-line treatment in 2015 were 77 with a success rate of $64 \%$ and $29 \%$ respectively [4] [5]. In Pakistan, treatment success rate in smear-positive pulmonary TB is $88 \%$ [6] [7] [8]. Historically, patients treated with 4 drugs combination have success rate and the chances of recurrence are very low i.e., $2 \%-3 \%$. Pakistan ranks 5th among 22 high TB burden countries and 4th among MDR-TB countries. Countrywide representative Drug Resistance Survey (DRS) was conducted in 2012 and the results showed that the estimated percentage of TB cases with DR-TB was $4.2 \%$ and $19.8 \%$ among New and Re-treatment cases respectively. While in 2016, there were $4.2 \%$ and $16 \%$ DR-TB cases in new and re-treatment cases making the annual burden of 14,000 new cases [9].

This retrospective study aimed to assess the notification rate of re-treatment $\mathrm{TB}$ cases among all enrolled TB patients and comparison of retreatment TB cases in public and private sector under provincial TB control program in district Swat in Khyber Pakhtunkhwa from 2015-2017.

\section{Methodology}

\subsection{Study Design and Study Population}

This is a retrospective cohort study based on a review of the collected data from TB registers. Retreatment tuberculosis (TB) represents those who have been treated previously these patients include relapses, treatment after failure, or loss to follow-upon a first-line treatment regimen. 
All enrolled retreatment TB patients from 2015-17 at 12 TB care facilities of district swat between January-2015 and December 2017 were included in the study.

\subsection{Data Collection}

The data was extracted through TB registers and TB treatment cards, Xpert MTB/RIF assay, culture and from a laboratory. For comparison-aggregated data of new pulmonary bacteriologically confirmed tuberculosis (NPBCT) patients were collected from the annual report.

\subsection{Statistical Analysis}

The aggregative data was extracted from the TB case notification register and treatment registers. Data were double entered in EPI data software version 3.1 and analyzed in SPSS version 16 and descriptive statistics were done to assess the characteristic of TB cases in Pakistan.

\subsection{Ethical Approval}

Permission to use the data and a local ethics exemption was obtained from the provincial TB control program, Khyber-Pakhtunkhwa. Since the study involved a review of records with no patient interaction, the informed consent was not required.

\subsection{Abbreviations}

National tuberculosis program (NTP), programmatic management of drugs resistant tuberculosis (MPDT), extended program of immunization (EPI), drug resistance survey (DRS), new pulmonary bacteriologically confirmed tuberculosis (NPBCT), retreatment tuberculosis (RT), multi-drug resistant tuberculo$\operatorname{sis}(\mathrm{MDR}-\mathrm{TB})$.

\section{Results}

At district Swat between January 2015 to December 2017, 8663 TB cases were registered as shown in Table 1 . Out of these 4520 (52.17\%) were men and 4143 (47.82\%) were women and $8540(98.58 \%)$ of the cases were newly diagnosed. Among these 1916 (22.11\%) were pulmonary bacteriological confirmed, 3498 (40.37\%) were pulmonary clinical diagnosed and 3396 (39.20\%) were clinically or bacteriological confirmed extra-pulmonary tuberculosis cases (shown in $\mathrm{Ta}$ ble 2). Retreatment TB patients were diagnosed and treated in Swat valley on the basis of a positive result for acid-fast bacilli using sputum smear microscopy and Xpert test.

Out of 8663 TB cases registered in district swat, 123 (1.41\%) were re-treatment cases. Table 3 shows majority of re-treatment cases were in the age group 18 - 43 years and only 7 patients were under the age of 15 years. Male to female ratio was $1: 1$. The mean age was 35.4 . 
Table 1. Trend of TB case notifications new and re treatment cases between 2015-2017.

\begin{tabular}{ccccc}
\hline Cases & 2015 & 2016 & 2017 & Total \\
\hline \multirow{2}{*}{ All cases } & $\mathrm{n}(\%)$ & $\mathrm{n}(\%)$ & $\mathrm{n}(\%)$ & $\mathrm{n}(\%)$ \\
New & 2065 & 3240 & 3358 & 8663 \\
Retreatment cases & $2049(99)$ & $3184(98)$ & $3307(98.4)$ & 8540 \\
\hline
\end{tabular}

Table 2. Trend of public and private TB case notification and general characteristics between 2015-2017.

\begin{tabular}{|c|c|c|c|c|c|c|}
\hline \multirow[b]{2}{*}{ Cases } & \multicolumn{2}{|c|}{$\begin{array}{l}2015 \\
\mathrm{n}(\%)\end{array}$} & \multicolumn{2}{|c|}{$\begin{array}{l}2016 \\
\mathrm{n}(\%)\end{array}$} & \multicolumn{2}{|c|}{$\begin{array}{l}2017 \\
\mathrm{n}(\%)\end{array}$} \\
\hline & Public & Private & Public & Private & Public & Private \\
\hline New & $1692(82)$ & 357 (17) & $2648(83)$ & $536(17)$ & $2677(80)$ & $630(19)$ \\
\hline Relapse & $13(81)$ & $4(0.7)$ & $44(78)$ & $17(2.6)$ & $28(53)$ & $17(32)$ \\
\hline $\begin{array}{l}\text { Treatment after } \\
\text { failure (TAF) }\end{array}$ & $2(12.5)$ & 0 & $12(21)$ & & $6(11)$ & 0 \\
\hline $\begin{array}{l}\text { Lost to follow up } \\
\text { (TAD) }\end{array}$ & $1(6.25)$ & 0 & & & 0 & 0 \\
\hline \multicolumn{7}{|l|}{ Gender } \\
\hline Male & $870(51)$ & $207(57)$ & $1414(53)$ & $288(53)$ & $1408(52)$ & $326(51)$ \\
\hline Female & 835 (49) & $150(42)$ & $1274(48)$ & $252(47)$ & $1296(48)$ & $321(50)$ \\
\hline \multicolumn{7}{|l|}{ Age group } \\
\hline $0-4$ & 255 (15) & $13(3)$ & 477 (18) & $20(3)$ & $527(19)$ & $6(1)$ \\
\hline $5-14$ & 707 (41) & $70(19)$ & $891(33)$ & $82(15)$ & $988(36)$ & $91(14)$ \\
\hline $15-24$ & 277 (17) & $101(28)$ & 485 (18) & $128(23)$ & 399 (15) & $168(26)$ \\
\hline $25-34$ & $152(9)$ & 68 (19) & $296(11)$ & $108(20)$ & $280(10)$ & $130(20)$ \\
\hline $35-44$ & $81(47)$ & $33(9)$ & $182(7)$ & $49(9)$ & $150(5)$ & $85(13)$ \\
\hline $45-54$ & $82(47)$ & $16(4)$ & $133(5)$ & $44(8)$ & $129(4)$ & $59(9)$ \\
\hline $55-64$ & $84(49)$ & $24(6)$ & $123(4)$ & $52(10)$ & $117(4)$ & $42(6)$ \\
\hline$>65$ & $67(39)$ & $32(9)$ & $101(3)$ & $6(1)$ & $117(4)$ & $66(10)$ \\
\hline
\end{tabular}

calculation of general characteristics are based on new cases.

Table 3. Characteristics of retreatment TB case between 2015-2017.

\begin{tabular}{ccccc}
\hline Age & New & Relapse & $\begin{array}{c}\text { Treatment after } \\
\text { failure (TAF) }\end{array}$ & $\begin{array}{c}\text { Lost to follow up } \\
\text { (TAD) }\end{array}$ \\
\hline $0-4$ & 0 & 0 & 0 & 0 \\
$5-14$ & 0 & 5 & 0 & 0 \\
$15-24$ & 0 & 25 & 8 & 1 \\
$25-34$ & 0 & 25 & 4 & 1 \\
$35-44$ & 0 & 15 & 3 & 0 \\
\hline
\end{tabular}


Continued

\begin{tabular}{ccccc}
\hline $45-54$ & 0 & 13 & 0 & 0 \\
$55-64$ & 0 & 5 & 3 & 0 \\
$>65$ & 0 & 13 & 2 & 0 \\
Gender & & & & 1 \\
Male & 0 & 48 & 6 & 1 \\
Female & 0 & 53 & 14 & \\
\hline
\end{tabular}

\section{Discussions}

This retrospective study was designed and done in DTC swat to determine the notification of re-treatment TB cases. In the current study, all the 123 retreatment TB patients record were reviewed and this is $1.41 \%$ among total between 2015 and 2017. The incidence is very low in 2015 but subsequently increased and higher in 2016 and 2017. The data suggest that individuals who have been successfully treated for TB are at an increased risk of developing TB again. Reported patients from all public health care facilities were $84.2 \%$ and from private $15.2 \%$. More retreatment cases were reported from public health care facilities as compared to private. This may be for the reason that fewer public health facilities are registered and health care providers at private level are less interested to provide TB care, and this could be another reason. As routine approaches are no longer adequate to combat with the vast, fragmented and largely unregulated non-NTP sectors in many countries. In some developing countries, more than half of patients prefer to seek private medical care. However, the private sector has often failed to provide high-quality TB care, which NTPs are well positioned to deliver [10]. Out of 10.4 million tuberculosis (TB) patients in 2015, 4.3 million were either not diagnosed or not notified to national TB programmes (NTP) [11]. This means that a staggering $40 \%$ of the TB patients globally are invisible to the public health system [12]. As private sector accounts for a considerable proportion of health care delivered in the country, it means that there are enormous gaps present in the system and it is a major threat to global TB control. In swat region, retreatment failure rates are lower than the cure rate which is almost $100 \%$.

Moreover, 101 (82.11\%) relapse, treatment after loss to follow up 2 (1.62\%) and treatment after failure $20(16.26 \%)$ were classified as retreatment TB. This suggests that individuals who have been successfully treated for TB are at an increased risk of developing TB again. Knowing about the profile of retreatment patients and the related outcomes of treatment is important to implement a "patient-centered care" approach which is based on a thorough understanding of the patients being served.

Findings of our study have shown that there was increased recurrence in male patients who are over 20 years old. However, it is concerning that adults over 40 years who are supposed to be responsible and thus more capable of understanding the importance of treatment, appear to be the ones who defaulted more [13]. 
The finding of our study suggests that retreatment is indeed a common phenomenon that should be given due attention. Another study [14] found that the rate of recurrence $\mathrm{TB}$ was $18 \%$ in the study population with recurrence occurring after successful treatment and after default. The re-infection rate after successful treatment was estimated at 2.2/100-persons/year. People with previous TB have a four times higher risk of TB compared to TB new patients.

Consistent finding on the effect of gender and default from TB treatment, most studies had shown that males are more likely to default TB treatment than females. This may partly explain the relatively large proportion of males with retreatment TB in this study. The finding of this study with regards to males is similar to others that have been reported from studies in Turkey, Nigeria, and India. In Turkey [14], the risk factors for non-successful treatment were determined to be re-treatment patients older than 46 years of age while in the Nigerian study [15] 44.2\% who defaulted treatment were older than 65 years and in India [13] not completing the process of diagnosis of TB was higher in $>50$ years age.

In our study, there was a limited data on Drug use, alcohol smoking, and HIV as it was not documented in our record. Indeed this is an important omission in the process of care of these patients which should be remedied realizing that there is some linkage between retreatment TB and these social habits. The previous study [16] among miners in South Africa has shown that HIV infection was associated with significantly increased rates of recurrent $\mathrm{TB}$ with an incidence of $8.2 / 100$ per year in HIV positive compared to 2.2/100 persons per year in HIV negative men. The need to test patients is recognized in the hospital however, patients can decline after voluntary counseling or confidentiality.

\section{Study Limitations}

As a retrospective study, limitation of this study is its retrospective design as the study relies on the previously collected data and some of the information was incomplete, like educational status, employment status, addictions among patients, and other socioeconomic factors of patients which may have an influence on the treatment outcomes were not studied.

\section{Acknowledgements}

This research was conducted through the Structured Operational Research and Training Initiative (SORT IT), a global partnership led by the Special Programme for Research and Training in Tropical Diseases at the World Health Organization (WHO/TDR). The training model is based on a course developed jointly by the International Union against Tuberculosis and Lung Disease (The Union, Paris, France) and Médecins Sans Frontières (MSF, Geneva, Switzerland). The specific SORT IT programme that resulted in this publication was implemented by the National Tuberculosis Control Programme of Pakistan, through the support of the Global Fund to Fight AIDS, Tuberculosis, and Mala- 
ria (The Global Fund, Geneva, Switzerland).

\section{Conflicts of Interest}

The authors declare no conflicts of interest regarding the publication of this paper.

\section{References}

[1] World Health Organization. (2018) Global Tuberculosis Report 2018. World Health Organization, Geneva.

[2] World Health Organization. (2003) Treatment of Tuberculosis: Guidelines for National Programmes. 3rd Ed. World Health Organization, Geneva.

[3] World Health Organization. (2013) Definitions and Reporting Framework for Tuberculosis-2013 Revision. Tech. Rep.WHO/HTM/TB/2013.2, World Health Organization, Geneva, Switzerland.

[4] Rusen, I.D. (2009) Tuberculosis Retreatment: A Topic Whose Time Has Come. International Journal of Tuberculosis and Lung Disease, 10, 1192.

[5] Tweya, H., Kanyerere, H., Ben-Smith, A., Kwanjana, J., Jahn, A., Feldacker, C., et al. (2011) Re-Treatment Tuberculosis Cases Categorised as "Other": Are They Properly Managed? PLoS ONE, 6, 1-5. https://doi.org/10.1371/journal.pone.0028034

[6] Alrajhi, A.A., Abdulwahab, S., Almodovar, E. and Al-Abdely, H.M. (2002) Risk Factors for Drug-Resistant Mycobacterium Tuberculosis in Saudi Arabia. Saudi Medical Journal, 23, 305-310.

[7] WHO. (2009) Pakistan: WHO Report 2009, Global Tuberculosis Control Programme. World Health Organization, Geneva.

[8] Tahseen, S., Qadeer, E., Khanzada, F.M., Rizvi, A.H., Dean, A., Van Deun, A., et al. (2016) Use of Xpert? MTB/RIF Assay in the First National Antituberculosis Drug Resistance Survey in Pakistan. International Journal of Tuberculosis and Lung Disease, 20, 448-455. https://doi.org/10.5588/ijtld.15.0645

[9] District and Tehsil Level Population Summary with Regional Breakup: Khyber Pakhtunkhwah. Pakistan Bureau of Statistics. 2018-01-03.

[10] World Health Organization. (2012) Involving Private Medical Practitioners in TB and STI Control. Report of an Informal Consultation Bangkok. World Health Organization, Geneva.

[11] World Health Organization. (2016) Global Tuberculosis Report, 2016. WHO, Geneva.

[12] Cazabon, D., Alsdurf, H., Satyanarayana, S., et al. (2017) Quality of Tuberculosis Care in High Burden Countries: The Urgent Need to Address Gaps in the Care Cascade. International Journal of Infectious Diseases, 56, 111-116. https://doi.org/10.1016/j.ijid.2016.10.016

[13] Verver, S., Warren, R.M., Beyers, N., Richardson, M., van der Spuy, G.D., Borgdorff, M.W., Enarson, D.A., Behr, M.A. and van Helden, P.D. (2005) Rate of Re-Infection Tuberculosis after Successful Treatment Is Higher than Rate of New Tuberculosis. American Journal of Respiratory and Critical Care Medicine, 171, 1430-1435.

[14] Talay, F., Kumeti, S. and Altin, S. (2008) Factors Associated with Treatment Success for Tuberculosis Patients: A Single Centers Experience in Turkey. Japanese Journal of Infectious Diseases, 61, 25-30.

[15] Salami, A.K. and Oluboyo, P.O. (2003) Management Outcome of Pulmonary Tu- 
berculosis: A Nine Year Review in Ilorin. West African Journal of Medicine, 22, 114-119.

[16] Karim, S.S.A., Churchyard, G.J., Karim, Q.A. and Lawn, S.D. (2009) HIV Infection and Tuberculosis in South Africa: An Urgent Need to Escalate the Public Health Response. The Lancet, 374, 921-933.

https://doi.org/10.1016/S0140-6736(09)60916-8 